\title{
Marroquíes Altos, Marroquíes Bajos. Origen y Toponimia ${ }^{1}$
}

\author{
Marroquíes Altos, Marroquíes Bajos. Origin and toponymy
}

\author{
Mercedes Navarro Pérez
}

Recibido: $23 / 03 / 21$

Aprobado: $13 / 05 / 21$

Publicado: $17 / 06 / 21$

\section{RESUMEN:}

La Zona Arqueológica de Marroquíes Bajos se encuentra al norte de la ciudad de Jaén. Los restos arqueológicos registrados en ella pertenecen a una cronología muy amplia que abarca desde la prehistoria hasta la actualidad. En estas breves líneas intentaremos acercarnos al significado de este topónimo asociado al lugar. Para plantear una o varias hipótesis hemos realizado un recorrido por las fuentes documentales, haciendo una revisión sobre la bibliografía publicada, así como de las intervenciones arqueológicas realizadas en el área de estudio. Este no es un topónimo demasiado frecuente en el territorio peninsular, sin embargo, en el entorno de la ciudad de Jaén aparecen al menos desde el siglo $\mathrm{XV}$, algunos parajes con este nombre. A lo largo de este trabajo exponemos que actividades como la marroquinería, o incluso, a algunas plantas, también se las denomina por el nombre de "marroquines". Sin embargo, la hipótesis que toma más relevancia es la relación con algunos linajes de mozárabes o judeoconversos.

Palabras clave: Arqueología, topónimo, Marroquíes.

\section{INTRODUCCIÓN}

"hay paisajes culturales más recientes en los que se han fosilizado conjuntos de significados que permanecen en la memoria y en los mapas ofreciéndose como la mejor de las fuentes para el conocimiento de la dimensión simbólica del paisaje: la toponimia" (ZAFRA, 2004: 23).

Marroquíes es el nombre con el que se conoce una extensa área de terreno situada al norte de la ciudad de Jaén. Esta, se encuentra dividida en dos zonas que, aunque unidas, se caracterizan por ubicarse a distinta altitud;

\section{ABSTRACT:}

The Archaeological Zone of Marroquíes Bajos is located to the north of the city of Jaén. The archaeological remains recorded in it belong to a very broad chronology, ranging from prehistoric times to the present day. In these brief lines we will try to approach the meaning of this toponym associated with the place. In order to put forward one or more hypotheses, we have made a tour of the documentary sources, reviewing the published bibliography, as well as the archaeological interventions carried out in the study area. This is not a very frequent place name in the peninsular territory although in the surroundings of the city of Jaén we can find, at least since the $15^{\text {th }}$ century, some places with this name. Throughout this work we will show that activities such as leatherwork, or even some plants, are also known by the name of "marroquines". However, the hypothesis that is most relevant is the relationship with some Mozarabic or Judeo-converted lineages.

Keywords: Archaeology, toponym, Marroquíes.

la primera se ha denominado Marroquíes Altos, al estar situada en la zona más elevada, a extramuros de la ciudad. La segunda se ha llamado Marroquíes Bajos y se encuentra en la parte más llana que ha sido ampliamente urbanizada en fechas recientes. Esta última es también conocida por dar nombre a una Zona Arqueológica declarada como tal a finales del siglo XX. Los restos arqueológicos registrados en ella pertenecen a una secuencia cronológica muy amplia, que abarca desde la prehistoria hasta la actualidad, con pequeños hiatos de abandono.

\footnotetext{
*Universidad de Jaén, mnperez@ujaen.es, https://orcid.org/0000-0001-6440-6737

1. Este trabajo se ha realizado en el marco del Proyecto I+D+i "La formación de la sociedad andalusí (SS. VIII-X). Los datos documentales y las evidencias materiales. Estudio de caso: Jaén” (Referencia HAR2017-87060-P), financiado por el Ministerio de Ciencia, Innovación y Universidades (Plan Nacional I+D de Excelencia) y la Unión Europea, a través del Fondo Europeo de Desarrollo Regional.
}

Cómo citar: Navarro Pérez, M. (2021): Marroquíes Altos, Marroquíes Bajos. Origen y Toponimia. Arqueología Y Territorio Medieval, 28. e6235. https://doi.org/10.17561/aytm.v28.6235 
Hasta 1995, este espacio se había dedicado, casi exclusivamente, a la agricultura. A partir de ese momento comienzan las obras para su urbanización como parte de la nueva expansión de la ciudad de Jaén hacia el norte. A pesar de que se había realizado una prospección arqueológica superficial en 1993 cuyos objetivos eran los de identificar y delimitar las zonas arqueológicas existentes en las áreas urbanizables propuestas en la revisión del Plan General de Ordenación Urbana, los resultados no fueron concluyentes por lo que hasta que comenzaron los trabajos y con ellos afloraron los primeros restos arqueológicos, no se comprendieron las dimensiones y potencial que tendría el futuro Yacimiento Arqueológico. Ante el peligro de la destrucción de los asentamientos que en ella se encontraban y, sobre todo, debido a la pérdida de información que se estaba produciendo, la Delegación de Cultura decidió su inclusión en el Catálogo General de Patrimonio de Andalucía. A partir de ese momento se haría obligatoria la realización de intervenciones arqueológicas con anterioridad a cualquier obra de edificación realizada en la Zona de Marroquíes Bajos.

El topónimo de Marroquíes con el que se denominaba a la zona, no es muy común para designar un territorio. El diccionario de la Real Academia define la palabra "Marroquí" como un adjetivo, que significa natural de Marruecos, perteneciente a este país de África, y tafilete (relativo al cuero). Nombre que procede del árabe marroquí (marrākuš; cf. port. marroqui $[m])$. Ante esta definición, nuestra pregunta era evidente: cuándo y por qué esta extensa zona de huertas recibió el nombre de Marroquíes.

Para intentar contestar a estas preguntas o al menos acercarnos a posibles respuestas se hacía necesario, en primer lugar, consultar las fuentes documentales que pudieran aclarar desde cuándo se utiliza este término asociado a Jaén, su significado o significados, a qué funcionalidad o circunstancias podía referirse, o qué grupos pudieron vivir o poseer estas tierras, hasta el punto de que dejaron en la memoria su nombre.

\section{FUENTES DOCUMENTALES}

Hasta el momento, cuando se hacía referencia al origen del topónimo de Marroquíes en Jaén, se enmarcaba cronológicamente en el siglo XIX. Como ejemplo un texto de S. Pérez (2003: 22):

Por lo que respecta al territorio que ocupa la ciudad de Jaén hay que tener en cuenta las dos áreas interrelacionadas que lo conforman desde antiguo: el Cerro de Santa Catalina delimitado por el perímetro amurallado y las tierras más bajas con extensas zonas de huertas, áreas que desde el siglo pasado vienen denominándose como Marroquíes Bajos.

Sin embargo, este término es mucho más antiguo, aparece por primera vez, al menos en la bibliografía consultada, en el año 1401, quedando recogido en los libros de las dehesas de Jaén, cuya información recoge Tomás Quesada, (QUESADA, 1994; ALCÁZAR, 2008). El documento realiza, como su propio nombre indica, una revisión del estado de las dehesas y caminos existentes a principios del siglo XV, para delimitar correctamente estos bienes. En ellos, aparece este topónimo refiriéndose a un área al norte de la ciudad de Jaén.

\subsection{Los repartimientos}

Tras la conquista de la ciudad de Jaén por Fernando III en 1246 y durante los dos años siguientes, el rey se dedicará a la repoblación de la ciudad y su entorno. Para ello otorgó a sus habitantes el Fuero de Toledo.

Las repoblaciones en el siglo XIII se realizaron según el modelo de repartimiento, entregando bienes tanto urbanos como rústicos a los repobladores. Según los libros de repartimiento estos lotes no solo se concedieron a los repobladores, sino que también se realizaron donaciones como botín por la conquista; algunas veces, una misma persona podía 
ser repoblador y beneficiario de donaciones (GONZÁLEZ, 1987).

Investigadores como Porras (2009) indican que esta primera repoblación se realizaría con los mismos mecanismos que los utilizados en las de Córdoba o Sevilla. Los bienes y los territorios se repartieron a las Órdenes Militares, como la de Calatrava o la de Santiago, y también a la Iglesia. En el caso de Jaén el rey dejó como teniente de la ciudad a don Ordoño, a quien encargaría continuar con el repartimiento que durante varios meses había supervisado él mismo, y en el que se respetaron, tal y como eran anteriormente, las heredades pertenecientes a algunos musulmanes.

La falta de documentación en Jaén con fecha anterior a 1368, incluidos los libros de repartimiento, es absoluta, ya que en este año se produjo la incursión de los nazaríes aliados de Pedro I. Durante dicha invasión, que duró cinco días y donde murieron o fueron apresados bastantes de los habitantes de la ciudad y sus alrededores, mayoritariamente descendientes de aquellos primeros repobladores, desapareció toda la documentación existente sobre los repartimientos.

La zona de la campiña, situada al norte de la ciudad de Jaén, estaba reservada a baldíos como usos comunales, y grandes cortijos que se corresponden con los donadíos restituidos después de 1368, en lo que es conocido como la segunda repoblación.

La población había disminuido considerablemente después de estos sucesos incluida la elite que tenía grandes propiedades, aunque perdurarán algunos linajes, como los Torres, los Contreras, Grañón o del Salto. Las tierras de aquellos que no sobrevivieron a la incursión serían ocupadas por nuevas familias que procedían del mismo reino de Jaén, cómo Arjona o úbeda, o de otros lugares.

Sepan quantos esta carta vieren cómo nos el concejo e cavalleros de la Muy Noble Cibdad de Jaén, por razón que a la sabcón que los moros enemigos de la fé con el Rey de Granada entraron esta cibdad e la robaron e quemoron e estruyeron, fueron perdidas e quemados las cartas e recabdos que los vezinos e moradores della tenyan de la dehesas y de sus heredades.... (PORRAS, 1997: 203).

\subsection{Marroquíes en los textos medievales y modernos}

El nombre de Marroquíes, en Jaén y describiendo un lugar, aparece por primera vez en la documentación escrita como Marroquis, haciendo referencia a una casa, imaginamos que una vivienda rodeada de un área de terreno. Posteriormente, las fuentes volverán a hablar de este sitio como Marroquíes, designando, primero, a un barranco o surco en la tierra realizado de forma natural y relacionado con las avenidas de agua y por último, a finales del siglo XV y hasta finales del siglo XX, asociado directamente con la tierra y la agricultura: pago, haza, huerta².

Es muy interesante un texto del año 1401 que versa sobre la delimitación de antiguas propiedades que habían resultado de los repartimientos tras la conquista y de las cuales no se conservan sus "cartas e recabdos" destruidas como consecuencia de la incursión nazarí de 1368. Habían pasado 33 años desde la destrucción de Jaén y aún se estaba intentando reconocer la delimitación de aquellas propiedades.

Es en este texto cuando aparece por primera vez el término Marroquis asociado a una vivienda rural. En este primer texto conservado,

\footnotetext{
2. Siguiendo la definición de la RAE, la diferencia entre este tipo de terrenos parece radicar, tanto en el tamaño como en el tipo de cultivos que se realizan en ella:

Pago: distrito determinado de tierras o heredades, especialmente de viñas y olivares.

Haza: porción de tierra labrantía o sembradura.

Huerta: terreno de mayor extensión que el huerto en el que se cultivan verdura, legumbres y árboles frutales.
} 
el topónimo se referirá a una vivienda que aparece nombrada como la casa de los Marroquis que se encontraba delimitando la Dehesa de Casatexada.

"E luego (roto) Sanches e Pero Fernandes (roto) por el juramento que fizieron que ellos (roto) syenpre se acostumbro guardar en los tiempos pasados desde vn poco ayuso de vn escaramujo que esta en la torrontera de vna madre vieja e desde alli que atravesava fasta vna quebrada que esta çerca de vna mata de frexnos e pusieron que esta en canto de vna madre vieja que esta a linde de tierras de Juan Sanches del Pariente, que pusyeron vun mojon de yuso del dicho escaramujo en la torrentera de la madre vieja e pusieron otro mojon/ en medio del masengar e pusieron otro mojon çerca de la mata de los frexnos (sic) e pusyeron otro mojon en la dicha quebrada por do sale el agua de la acequia que sale de los molinos del Pozuelo por la dicha casa de los Marroquis. Este mojon esta açerca de vn tarahe de la dicha quebrada e pusyeron otro mojon açerca de la dicha açequia. Y que esta dehesa que sea guardada desde otros mojones hasta la casa e que la tierra que esta destos mojones arriba hasta la dicha açequia e con el rincon que esta de parte de arriba del mojon del escaramujo hasta la dicha açequia que la coman los ganados de los vexinos e moradores de Jaen e del su termino e syeguen la yerva los que los obieren manester e dixeron por la jura que hizieron que siempre lo vieron asi vsar en razon desta dehesa en los tiempos pasados e ante del enterramiento de la dicha çibdad. Juan
Sanches de Martos, escriuano publico" (QUESADA, 1994: 118-120).

La dehesa que está describiendo y en la que se encontraba la casa de los Marroquis, aun hoy puede reconocerse en el paraje denominado el Pago de Pozuela, situado al norte de la ciudad de Jaén, que actualmente conforma una de las urbanizaciones que rodean la ciudad, y que cuenta con unas 250 viviendas unifamiliares; la presencia de un gran barranco ocupando gran parte del barrio es una de sus características (Fig. 1).

La alusión a elementos hidráulicos, acequias, madresviejas, molinos, etc., es y será muy importante en todo este relato. Nos está describiendo un paisaje que, como en otros casos (la huerta de Valencia o de Murcia), vendría heredado del mundo andalusí y relacionado con el regadío, algo que se ha documentado ampliamente en las excavaciones realizadas en la zona arqueológica.

En este texto, la casa de los Marroquís se sitúa junto a la salida del agua de una acequia que parece proceder del molino de la Pozuela.

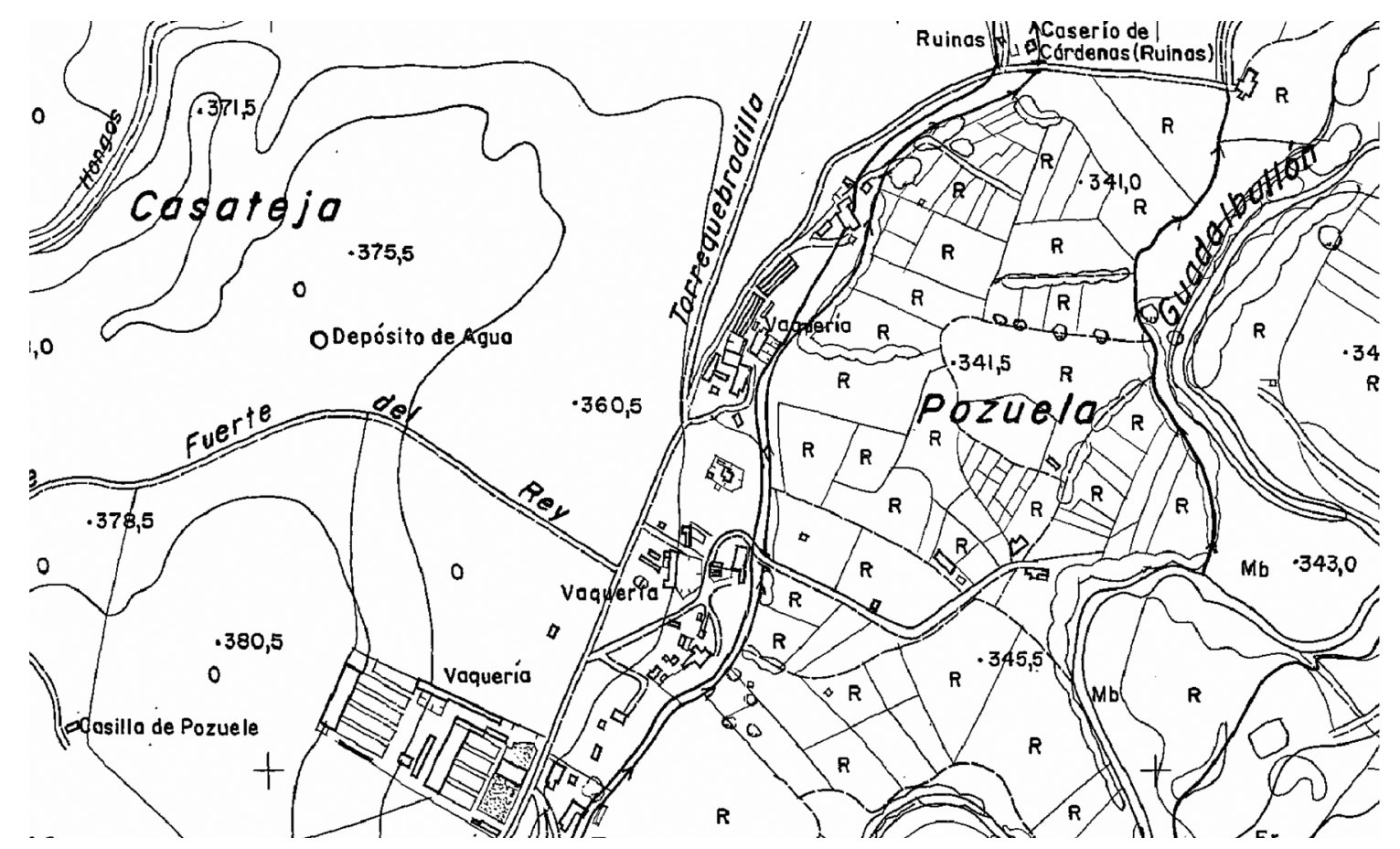

Fig. 1. Localización de Casatejada y Pozuela. Hoja Cartográfica 1. 10.000 
La madrevieja es una gran canalización, eje del que parten otros menores que distribuyen el agua por el territorio y que, como hemos visto, nacía en este molino. Actualmente existe una estructura de estas características, un complejo sistema de acequias que cuenta con más de 20 kilómetros de longitud y que se extiende desde el paraje de Guadaodalla hasta la zona conocida como las Infantas, pasando por Casatejada o la Puzuela. Sin embargo, este medio de irrigación parece pertenecer al siglo XIX, aunque no se descarta que para su realización se aprovechara parte de las infraestructuras anteriores (ALCÁZAR, 2008).

Las acequias y canales documentados en la Zona Arqueológica de Marroquíes Bajos existen desde antiguo, sucediéndose en el tiempo hasta llegar al siglo XX. En este siglo las acequias se distribuían a lo largo de las lindes de las parcelas, lo que ha llevado a pensar en la relativa contemporaneidad de estas; sin embargo, no podemos descartar una continua reutilización y modificaciones puntuales en la misma.

\section{Texto de 1410. Reconocimiento de las veredas y dehesas de Jaén}

Nueve años más tarde del primer documento, en el año 1410, de nuevo, el alcalde y once vecinos de Jaén, junto a dos escribanos, fueron a dar testimonio de la situación de las veredas y dehesas de Jaén "en los tiempos pasados". En este nuevo texto se vuelve a repetir el mismo topónimo, esta vez terminado en ies y asociado a un barranco:

"3 (roto) E luego los sobredichos (roto) escrivanos fueron a los (roto) del molino de (roto) termino de jaen e los dichos Benito Sanchez e Goncalo Fernandes e Alonso Martines e Juan Alonso e Domingo Gil so dixieron quel vado del Sabzejo desde el barranco de los Marroquies hasta la torrentera da Barranco Hondo en Guadalbollon de esta parte del ryo e de aquella otra parte del ryo hasta las Peñas de Allozar que fue otro tiempo vereda todo con que venían a veber aqua los ganados de Jaen. E que así lo vieron usar ellos e otros muchos en los tiempos pasados" (QUESADA, 1994: 102).
Los escribanos salen de un molino, que con toda probabilidad se trata del Molino del Pozuelo ya que en el texto anterior la casa de los Marroquíes estaba asociada a este pago. En el escrito se hace referencia al vado del Sabzejo. Este paso es nombrado, ya como tal, en los documentos de 1378, refiriéndose a él como lugar desde donde partían los regidores giennenses para realizar el control de vados y veredas (QUESADA, 1994; ALCÁZAR, 2008)

Probablemente desde esta antigua vía, según el documento, los regidores partían del Barranco de los Marroquíes y en su itinerario, tras pasar cerca de Casatejada y cruzar el río Guadalbullón llegaban, como hemos indicado anteriormente, al paraje de Barranco Hondo y las Peñas del Ayozar. El nombre que recibía este vado existe aún hoy, en el topónimo de un puente a 500 metros del cortijo de Casa Tejada; dicho paso permitía la circulación del ganado de un lado a otro del río (ALCÁZAR, 2008). Es por esto por lo que nos inclinamos a pensar que el documento se refiere a la misma zona que en el año de 1401 se denominaba como dehesa de Casa Tejada y que vimos con anterioridad.

Por otro lado, también podemos encontrar en la cartografía de finales del siglo XIX la situación de un cortijo y salinas denominadas Barranco Hondo al otro lado del río Guadalbullón, al sureste del cortijo de Casa Tejada. Estas salinas aparecen por primera vez nombradas en las Actas Capitulares de 1479 y se encuentran enclavadas en el fondo de dicho barranco. Puede ser por esto por lo que no son citadas en la descripción realizada en 1410, donde el objetivo principal era reconocer el estado de los caminos.

Si bien estos topónimos han pervivido hasta la actualidad, el barranco de los Marroquíes no es reconocible, al menos, como un accidente geográfico, o asociado a alguna estructura de tipo acortijado, sino que actualmente se adscribe a una amplia zona situada a $6 \mathrm{~km}$ al sur de Casa Tejada (Fig. 2). 


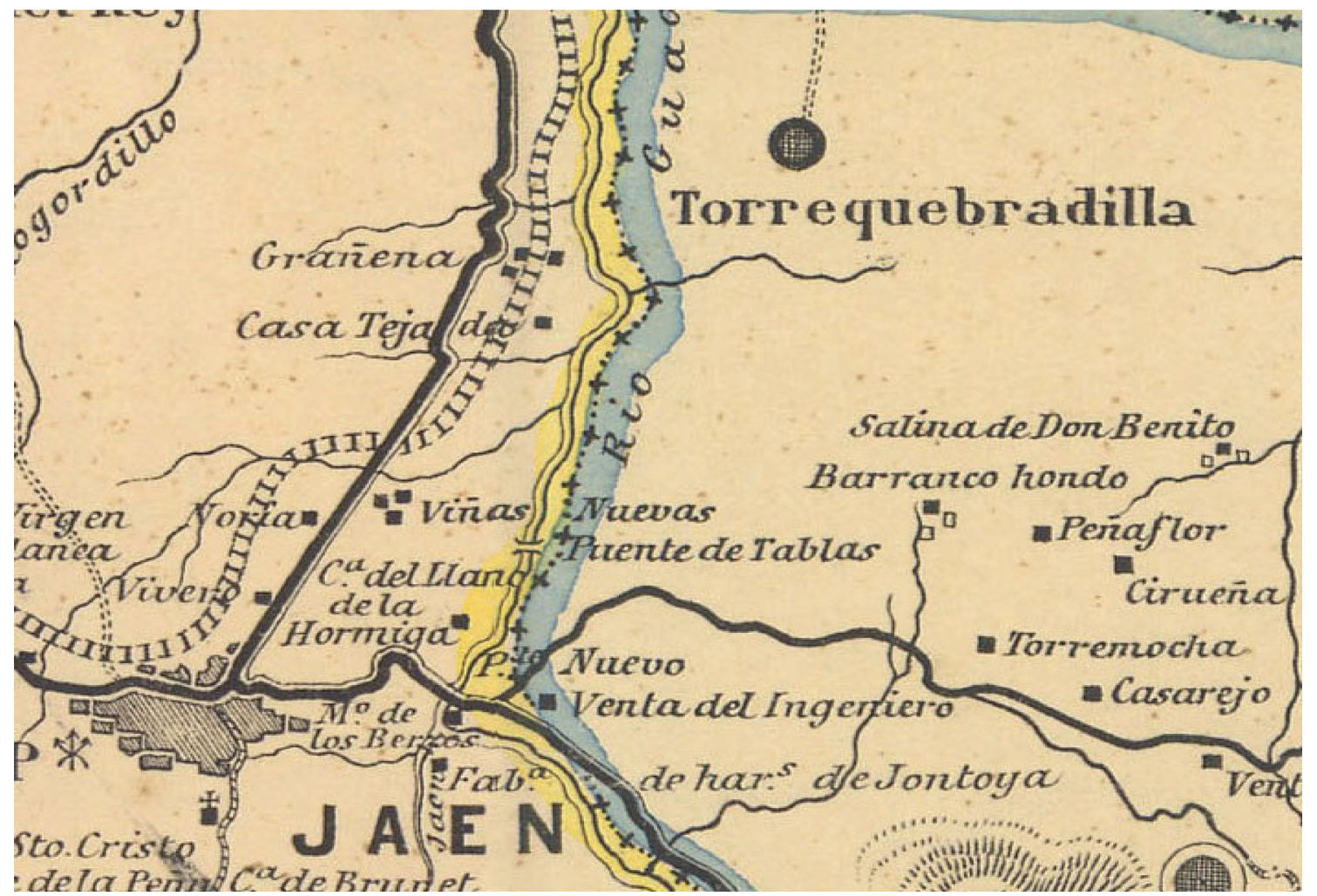

Fig. 2. Casa Tejada. Plano de 1872

Al noreste de la Zona Arqueológica de Marroquíes Bajos, con anterioridad a su urbanización, existía un barranco, probablemente natural, que discurría paralelo a la carretera de Madrid y que se situaba junto a la necrópolis de época islámica a la que se ha denominado maqbara del camino de Bayyāsa, por encontrarse junto a esta importante vía de comunicación a su paso por Marroquíes (NAVARRO, 2017) (Fig. 3).

Dicho camino partía de una de las puertas principales de la ciudad, la Puerta Baeza o de Bayyāsa, y descendía dirigiéndose al norte, hacia la campiña, atravesando todas las huertas de Marroquíes Altos y Bajos, hasta llegar a un punto, en el extremo noreste de la Zona Arqueológica, donde se encontraría con el barranco anteriormente mencionado. Esta zona, al menos en los siglos XIX y XX, era un punto donde el camino se bifurcaba en una vía principal que seguía hacia el norte, la actual carretera de Madrid, y otra hacia el este, buscando el valle del Guadalbullón, que iba hacia Baeza.
La primera referencia que tenemos sobre este camino y las dos variantes que existían del mismo, pertenece al siglo XVIII. Será Antonio Ponz quien lo describa en su libro Viaje de España, en que se da la noticia de las cosas más apreciables, y dignas de saberse, que hay en ella (LÓPEZ, 2018). Las dos variantes a las que nos referimos son: la que llega a Baeza desde Jaén a través del Puente del Obispo, mientras que la segunda opción se dirige por el camino de Torrequebradilla. Será este último el que, en parte de su recorrido, desde Jaén y una vez atravesada la actual Zona Arqueológica, irá paralelo al río Guadalbullón hasta llegar al Cortijo de Casa Tejada donde un paso, vado del Sabzejo, al que nos hemos referido anteriormente, permite el acceso al otro lado del río. Por este, según el texto del siglo XV, cruzaba habitualmente en época bajo medieval el ganado de un lado al otro. A partir de aquí, una vez en el lado este del Guadalbullón, el camino seguía hasta llegar a las peñas de allozar (Fig. 4). Actualmente podemos reconocer todo un paraje con esta denominación al sureste del puente. 


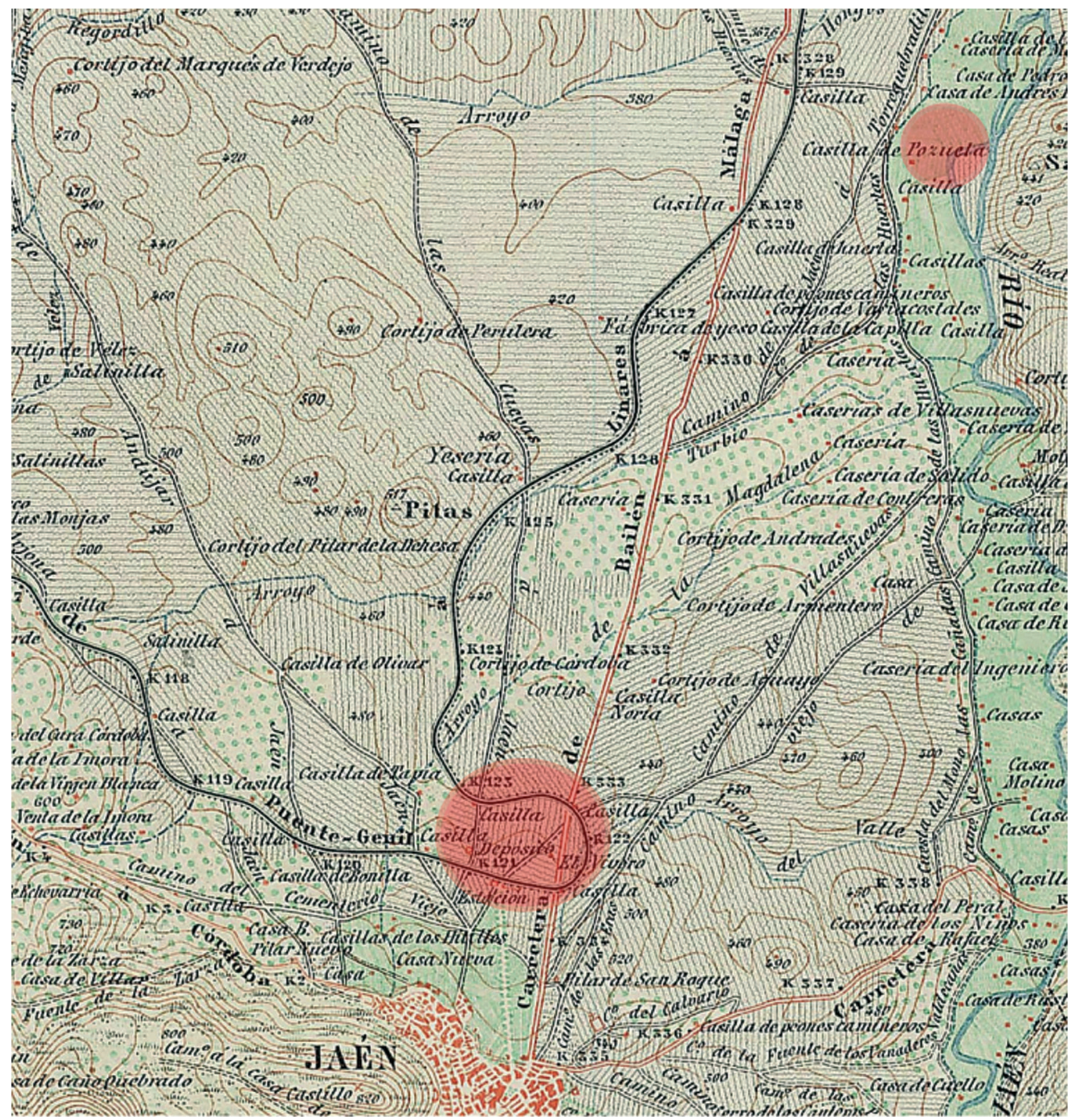

Fig. 3. Situación de la Zona arqueológica de Marroquíes Bajos respecto al Pago de la Pozuela

\section{Texto de 1500. El pago de los Marroquíes}

Como hemos visto, en un primer momento, en el documento de1401, se menciona La casa de los Marroquís, y posteriormente El barranco de los Marroquíes, pero en ambos casos se refiere a elementos individuales que, posiblemente conformaban un pago que se extendía más al norte y este de lo que hoy es la Zona Arqueológica, como hemos podido apreciar por los topónimos que aún son reconocibles, abarcando un área mayor que la actual.
Porras Arboledas (2009) en el estudio realizado sobre el oficio de alcalde recoge un documento del año 1500 donde explica cómo eran nombrados los alcaldes de propios, denominados así porque eran elegidos entre los propietarios de una finca rustica o de ganado, y para ello escoge como ejemplo un documento en el que aparece, por primera vez, como tal, El pago de los Marroquíes.

"los doce propietarios de fincas en el pago casi urbano de Los Marroquíes, quienes eligen a dos de ellos (Juan López de Cantos y Juan López de la Hoya) como alcaldes de su acequia" (PORRAS, 2009: 129). 


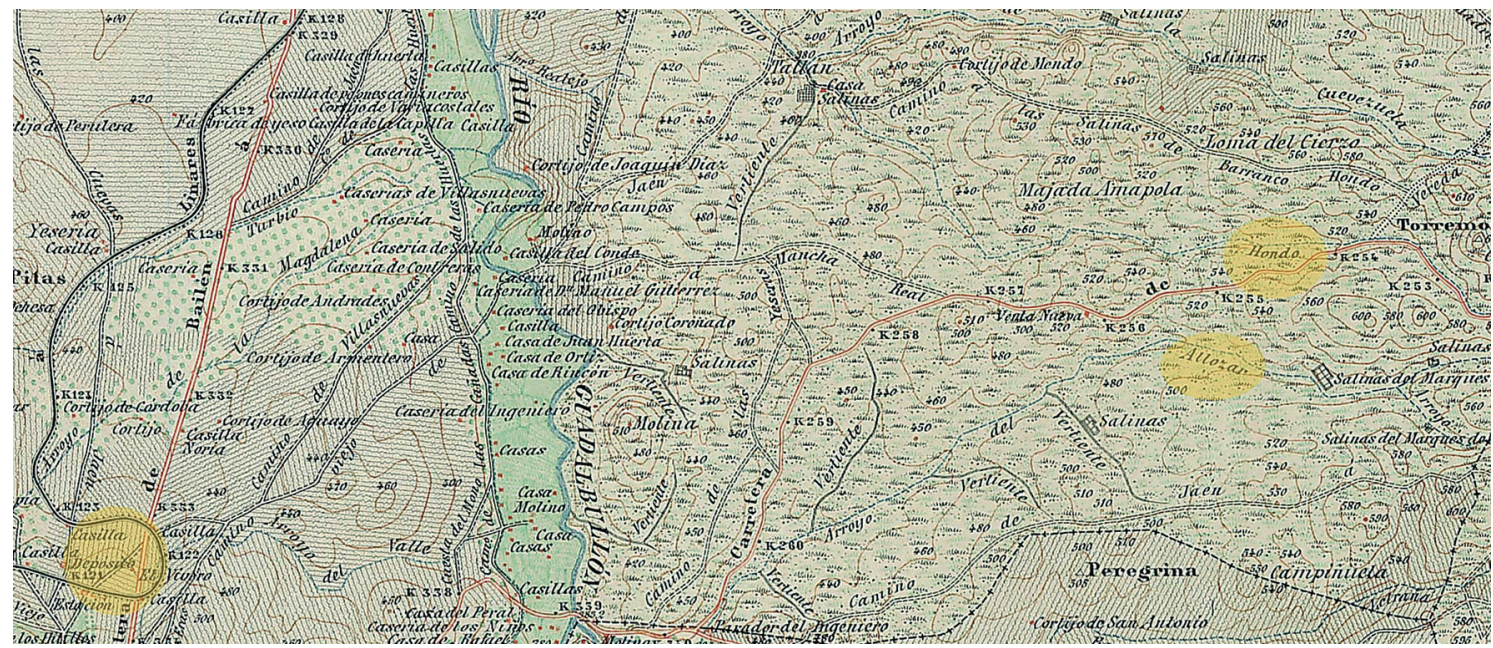

Fig. 4. Localización. Barranco Hondo y el Allozar

"Un pago casi urbano", esta frase nos indica que dichos campos estarían muy cerca de la ciudad, o lindando con ella. Hasta este momento las descripciones que se realizaban donde aparecía este nombre estaban a $5 \mathrm{~km}$ de la ciudad, distancia excesiva, en nuestra opinión, para poder denominarlo como pago casi urbano. Por tanto, podemos plantear como hipótesis la existencia, tal y como ocurre actualmente, de dos espacios que reciben este topónimo. El más cercano a la ciudad, Marroquíes Altos, pago casi urbano, y otro, Marroquíes Bajos, más alejado de la misma que, en un primer momento, no es tanto un pago sino elementos como una casa o un barranco pertenecientes a los Marroquíes. Otro tema es el porqué de este nombre, problema que abordaremos más adelante.

La ciudad de Jaén estaba rodeada de las denominadas Huertas de Poyo o de Rivera que también eran conocidas como Ruedos desde época bajomedieval y tenían una extensión aproximada de 58 hectáreas, abarcando un territorio que iba desde la Puerta de Martos a la Puerta Barrera.

Las huertas más cercanas a la ciudad, localizadas entre esta y el camino de Peñamefecit, tenían como producción característica la hortaliza común (RODRÍGUEZ, 1996). Se regaban con el agua del matadero y las sobrantes del arroyo de la Magdalena, conducido y utilizado en el interior de la ciudad. Estas huertas, a su vez, estaban lindando con la zona de Vega que se correspondía con El coto de la Veintena, nombre recogido en una carta de los Reyes Católicos en la que daban orden de que por cada veinte cabezas de ganado que entrasen en el coto, se multaba al agresor con una o más por el daño causado a las siembras, olivos y viñas (LÓPEZ, 2003). En estas parcelas la producción era de trigo, cebada, habas, olivos de regadío, entre otras, ocupando una extensión de 900 ha.

La zona de Marroquíes o pago de los Marroquíes debía de encontrarse dentro de los límites de lo que se denominaba la Vega, según los términos que Martínez de Mazas describe en Retrato al Natural de la Ciudad de Jaén y su Término:

"Desde la Dehesa aquende las Viñas del Majano por Belbel, el Molinillo, la Saceda. Fuente del Prado, Torrejón del Valle, la Peña Almagra hasta Valdeparaíso por donde entra el arroyo en el Río, y hasta Jaén: así se explicaban los términos de dicho coto, que es puntualmente toda la Vega á donde alcanzan las aguas de riego empezando por la punta de arriba ó se desde la Virgen blanca, por donde baja la Agua de la Imora y de las Casas, y después la de la Fuente de la Magdalena, Arroyo del matadero y Fuentecillas de la Salobreja y hasta el Vado de media noche por donde entra en Riofrío el Arroyo de Valdeparaíso" (MARTÍNEZ DE MAZAS, 1996: 357).

Aunque algunos de los lugares que se mencionan en este párrafo han cambiado de nombre, la mayoría de ellos se conserva, por 
lo que se puede realizar un recorrido aproximado de cuáles serían los límites y comprobar que la Zona de Marroquíes Altos y Bajos queda en su interior. Sin embargo, los topónimos que hemos visto con anterioridad, La Pozuela, Casa Tejada y, por ende, la casa de los Marroquíes quedarían fuera, aunque lindando con ella.

Por otro lado, hemos comprobado que los metros cuadrados a los que hace referencia el texto que describe la Vega, expresados en hectáreas, y que se corresponden con cada una de las áreas nombradas, coinciden con las dimensiones que hemos marcado (Fig. 5).

1. Zona donde se une el arroyo de Valparaíso en Riofrío. Área de Valparaíso.

2. Peña Almagra, actualmente conocida como Cerro Almagro, junto a la ubicación del Estadio Municipal de la Victoria (campo de fútbol).

3. Torrejón del Valle. En realidad, no hemos podido encontrar en cartografía dicho torrejón, pero sí un área que se denomina el Valle.

4. Fuente del Prado, en el siglo XIX, principios del XX, existía un paraje, al norte del anterior, denominado Los Prados, del que tomará nombre un sanatorio psiquiátrico construido a mediados del siglo XX. Creemos que Martínez de Mazas podía referirse a este paraje.

5. Al noroeste del punto anterior encontramos una zona denominada el Molinillo. Si seguimos el orden por el que Martínez de Mazas los va nombrando, entre este punto y el anterior nos falta la Saceda, área no reconocida en planimetría antigua, ni actual. Tampoco hemos podido identificar la Dehesa aquende las Viñas del Majano por Belbel, que se encontraría al oeste del Molinillo, si el orden fuera correcto.

6. Por último, el autor dice que los extremos de dicha delimitación son Valparaíso, ya nombrado en primer lugar, y el otro, numerado por nosotros con el 6, lo constituiría el paraje de la Virgen Blanca.

\section{Documentación de la segunda mitad del siglo XVII. Haza de Marroquíes}

En 1682, Gaspar de la Justicia, racionero de la catedral de Jaén, hace testamento y, entre otros, deja unos bienes en Jaén para construir un colegio y garantizar su supervivencia. Con el tiempo, según indica López (2004b), el patrimonio se vio incrementado con la adquisición de varias propiedades y, entre ellas, de nuevo aparece el nombre de Marroquíes, esta vez como haza.

"Con varias hazas en el término de Jaén, ubicadas en Villar de Cuevas, el Zumel, el Cementerio, las Casillas, las Fuentezuelas, la Vegueta de Santa Isabel, la Virgen Blanca y Marroquíes; y dos huertas, en Las Freilas, y Otiñar. Igualmente, a su caudal se incorporaron seis olivares en Baños de la Encina; y otros seis olivares y tres censos en Mancha Real" (LÓPEZ, 2004b: 91).

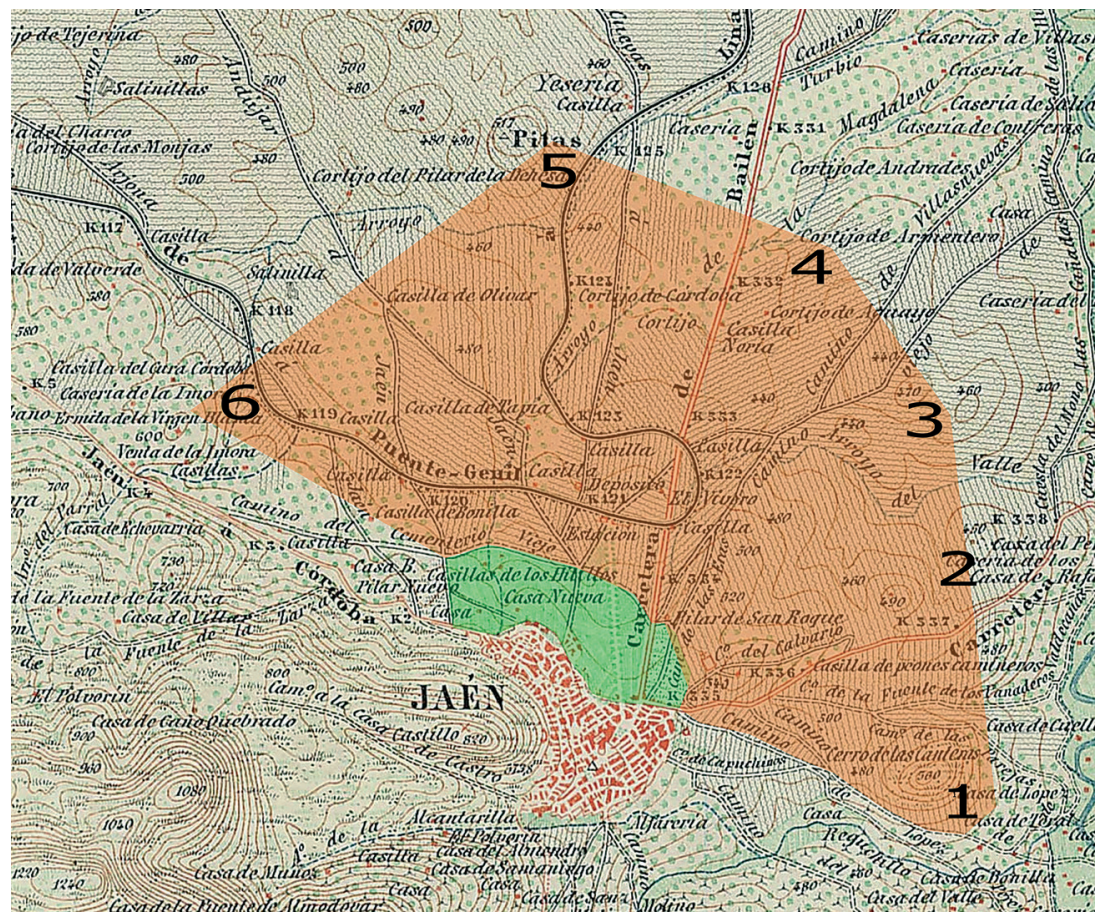

Fig. 5. Delimitación de la Vega 
El orden en el que se enumeran las hazas no se corresponde con la situación en el territorio. Todos los topónimos a los que se refiere el texto son perfectamente reconocibles actualmente. Lo que tenemos que destacar es que, a principios del siglo XVI, como vimos anteriormente, nos referíamos a Marroquíes como un pago, aunque en el texto de la segunda mitad del siglo XVII se habla de un haza en Marroquíes. Según el Diccionario Académico de Autoridades de 1734, un haza es "el campo donde se ha segado trigo ù otra semilla, y que está ocupado de los haces y gravillas que han hecho los segadores: y también se llama así una cierta porción de tierra, aunque no esté sembrada" (GARCÍA, BRAZILLE, 2010:11). Considerando que un haza es una porción de terreno, en este caso se refiere a una propiedad que se encontraría englobada en el pago de los Marroquíes.

\section{Documentación del siglo XVIII. Haza o Huerta de los Marroquíes}

En el siglo XVIII, este topónimo aparece en dos documentos muy importantes, a través de los cuales podemos reconocer cómo era el paisaje urbano y el entorno más cercano de la ciudad de Jaén:

\section{-- El catastro del Marqués de la Ensenada}

El catastro del Marqués de la Ensenada se realizó a mediados del siglo XVIII con el fin de sustituir los impuestos incluidos en las rentas provinciales llamándose Única Contribución. Para ello era necesario averiguar la riqueza existente en cada provincia, por lo que se encargó al administrador de cada una de ellas la formación de grupos que la realizaran. Estos grupos recogieron la información más relevante sobre propiedades rústicas y urbanas, ganados, censos, etc. La Única Contribución nunca llegó a establecerse, pero la información aportada por este catastro es una documentación esencial para conocer cómo eran estas parcelas y edificios y, además, nos permite realizar una aproximación a la vida social y económica, en este caso, de la provincia de Jaén (DEL ARCO, 2002).
Entre 1750 y 1754, en este Catastro aparece Marroquíes como un haza perteneciente a la Hacienda de la Santa Capilla de San Andrés (LÓPEZ, 2004a). Las posesiones de la Iglesia entre los siglos XVI y XVIII en Andalucía conformaban hasta un $20 \%$ de las fincas rústicas y urbanas (LILLO, ÁLVAREZ, 2006).

No vamos a entrar en detalles sobre toda la documentación existente relativa a las hazas y huertas que en el siglo XVIII se describen en el Catastro pertenecientes a este pago, y que necesitarían un estudio solo para este momento. El objeto de nuestro trabajo solo pretende rastrear el topónimo a lo largo de la historia en el entorno de la ciudad de Jaén y buscar su probable significado.

-- La obra de Martínez de Mazas: Retrato al Natural de la ciudad y Término de Jaén.

A finales del siglo XVIII, volvemos a encontrar, en la documentación escrita, referencias al topónimo de Marroquíes. Martínez de Mazas indica, en su obra Retrato al Natural de la ciudad y Término de Jaén, y refiriéndose a la Vega, un paraje denominado como haza o huerta de los Marroquíes.

"Pero volvamos a nuestra vega: y sentado que esta se debe de guardar de todos los ganados como coto riguroso, y que así se guardaba aún en el siglo pasado, ¿que dificultad puede haber en plantar en ella olivos y morales? Estos no necesitan de tanto riego como las hortalizas, y plantándolos como he dicho en las margenes de las hijuelas por donde pasa el agua para las hazas, y en las lindes de cada un, sin más riego que la humedad contigua saldrán frondosos. Veanse los que han quedado en la primera haza, ó huerta de los Marroquies a orillas del arroyo del Matadero..." (MARTíNEZ DE MAZAS, 1996: 360).

Por este texto sabemos que esta primera haza o huerta llamada de los Marroquíes, probablemente por encontrarse en el antiguo pago de los Marroquíes, tenía olivos y morales delimitando la parcela. Otro dato que nos será muy útil para localizar su situación es que se encuentra a orillas del arroyo del Matadero.

A finales del siglo XVIII, el antiguo matadero de Jaén, fundado en 1463, se encontraba cerca 
de la plaza del mercado, junto a la puerta Barrera, y estaría en funcionamiento hasta que en 1882 se demoliera para abrir el Paseo de la Estación que uniría la ciudad con la estación del ferrocarril.

Por otra parte, por la antigua Plaza del Mercado, hoy Plaza de la Constitución, discurría un arroyo llamado de las Avenidas, porque recogía las aguas sucias de la ciudad. A lo largo de su recorrido iba acumulando aguas sobrantes de otros arroyos y fuentes, uniéndose al llamado arroyo del Matadero, el cual se dirigía hacia la Vega donde, como hemos visto, se encontraba el pago de los Marroquíes y esta primera huerta del mismo, delimitada por olivos y morales.

En el plano topográfico de Jaén, levantado por Francisco de Quesada en 1819 (Fig. 6), aparece el arroyo del Matadero y se puede apreciar cómo se une a otro que no viene nombrado y que, probablemente, sería el arroyo de las Avenidas; el punto de unión se realiza en un cruce de caminos donde se localiza un puente.
Resumiendo, el nombre de Marroquíes aparece reiteradamente vinculado a la Vega de Jaén y su entorno más cercano, en el lado norte de la ciudad, primero en el siglo XV, como casa de los Marroquís y barranco de los Marroquíes. Sin embargo, en los relatos posteriores desaparece la nominación a estructuras para hacer una designación más general pero siempre relacionada con el campo: a finales del siglo XV se denomina pago de los Marroquíes (terreno dedicado a olivos o viñas), en el siglo XVII aparece como haza (terreno dedicado a la labranza) y, por último, en el siglo XVIII como Huerta de los Marroquíes (terreno donde se cultivan verduras, legumbres y árboles frutales). Lo que parece claro es que ha existido un paraje con este nombre dedicado a la agricultura, quizás cambiando de tipos de cultivo, desde antiguo, aunque probablemente con el paso de los años fue reduciendo sus dimensiones, pero conservando su topónimo.

Sobre los propietarios del mismo sabemos que a finales del siglo XV y principios del XVI, en el pago casi urbano de Marroquíes eran, al

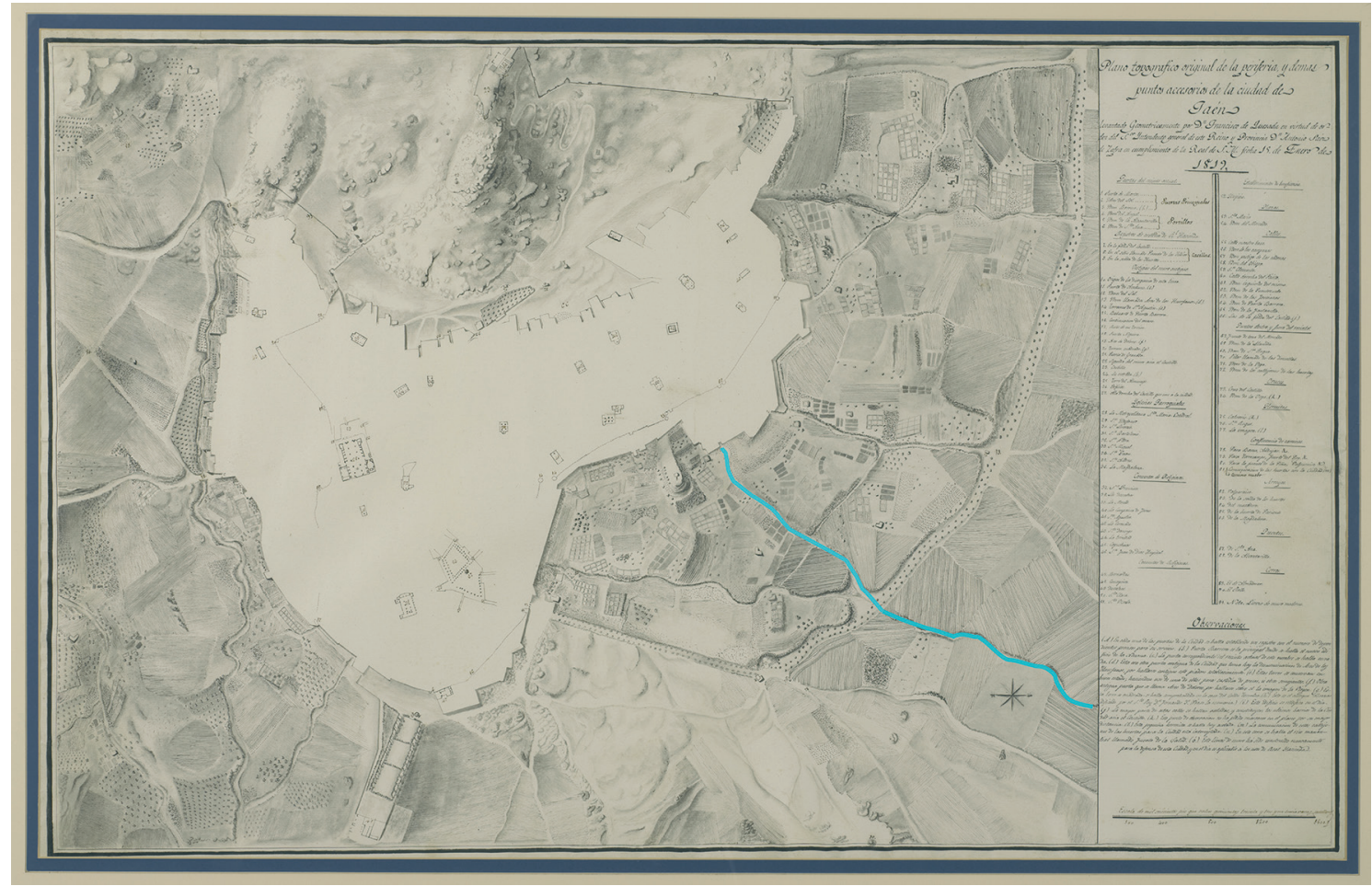

Fig. 6. Plano de Jaén. 1819 
menos, doce los propietarios de fincas dentro de sus límites. De ellos conocemos dos nombres, Juan López de Cantos y Juan López de la Hoya. A finales del siglo XVII, algunos de estos terrenos aparecerán vinculados con la Iglesia o instituciones ligadas a ella. Gaspar de la Justicia, racionero de Jaén, funda el Colegio del Santísimo Sacramento y, como vimos con anterioridad, en su testamento deja a este una serie de bienes para sus gastos; la Haza de Marroquíes se adquirirá posteriormente a su muerte, incluyéndola en las posesiones del colegio. Las propiedades rústicas serían arrendadas para incrementar sus rentas y garantizar la supervivencia de la institución (LÓPEZ, 2004a). Otro propietario de hazas situadas en Marroquíes es la Cofradía de la Capilla de San Andrés, fundada a principios del siglo XVI por Gutierre González Doncel aportando parte de su fortuna, entre otros bienes, varias fincas. Con el tiempo la Santa Capilla incrementó el número de devotos y con ellos la posesión de nuevas fincas, hasta tal punto que esta institución se convertirá en uno de los poderes con más propiedades rurales, principalmente irrigadas, del término de Jaén.

\section{MARROQUÍ, MARROQUINERO, MARROQUINES, MARROQUÍN}

Los topónimos generalmente son una fuente de datos que, analizados con detenimiento, nos pueden llevar a reconocer procesos históricos, reflejando acontecimientos que pasan a ser testimonios del pasado.

Este apartado se centra en la investigación sobre el origen del topónimo referido a esta zona cercana a Jaén dedicada a la agricultura desde antiguo, además de intentar aclarar las características que le hicieron merecedor de esta denominación. Para ello, veremos los significados, las ideas o conceptos que pudieron identificarlo, aunque hay que tener en cuenta que no todos los topónimos hacen referencia a características del lugar que designan, como aparentemente sería nuestro caso.

\subsection{Marrakech, Marruecos}

En los textos bajomedievales referentes al entorno de la ciudad de Jaén, este topónimo se asocia, en principio, a una propiedad: la casa de los marroquíes y más tarde a un accidente geográfico: el barranco de los marroquís, para después extenderse hasta referirse a un paraje o pago localizado en una zona más cercana, al norte de la ciudad.

Como vimos en la introducción, el diccionario de la Real Academia indica que la palabra "Marroquí" procede del árabe marroquí (marrākuš; cf. port. marroqui[m]), adjetivo que significa natural de Marruecos, perteneciente a este país de África. Aunque también tiene otro atributo relacionado con una región del sudeste de Marruecos llamada Tafilete donde se preparaban cueros bruñidos más finos que el cordobán.

Por tanto, la primera hipótesis a plantear es que los recursos, casa o barranco, eran propiedad de personas o familias procedentes de Marruecos, para extenderse luego ese nombre a un área de territorio más extensa, que probablemente ya no pertenecía a un solo propietario. Pero esta teoría, en principio la más lógica, presenta varios problemas. En primer lugar, en el vocabulario medieval, al menos el recogido en los textos y documentos, para referirse a los habitantes del norte de África se utiliza la palabra "moros" (MARTínEZ, 2009: 335). En segundo lugar, en el siglo XIV, fecha en la que era usado este nombre en el área de estudio, el territorio donde hoy se integra Marruecos era conocido como Al-Magrib al-Aqșà, lo que se traduce como Extremo Magreb o Extremo Poniente, diferenciándolo de la región llamada Magreb y que incluiría otros países actuales como Túnez y Argelia. Sin embargo, existía la ciudad de Marrakech, antigua capital almorávide y almohade. Marrakeches una expresión que se forma de la combinación de dos palabras beréberes Mur-Akuc, lo que significa Tierra de Dios. Marrakech fue fundada en 1062 por los almorávides, que tras conquistar parte del territorio de Al-Magrib al-Aqșà entraron en al-Andalus. Posteriormente, en 1147 los 
almohades conquistaron la ciudad y los territorios de la península. En los siglos XII y XIII, su lengua, el amazigh, adquirió una gran importancia, aunque en palabras de M. Fierro (2007) "no tenemos aún clara la política lingüística de los califas almohades" y aunque no parece que llegara a ser el idioma oficial como indica LLorent-Vedmar (2014), sí que los textos doctrinarios más básicos del movimiento fueron escritos en beréber.

Sin embargo, la presencia cristiana en Marrakech, en contra de lo que pudiera parecer, ha sido una constante que se inicia con la llegada a la ciudad de cinco franciscanos en 1220, pero también encontramos cristianos que residen en esta ciudad por motivos comerciales, o como soldados o esclavos. Las crónicas reflejan un continuo traslado de cautivos, de forma que, para Martínez (2011), parte de los cristianos cautivos pasaron a ser incluidos o formando parte del ejército de mercenarios integrados en las tropas almorávides que llegaron a Toledo en 1147, después de la caída de Marrakech en manos de los almohades según narra la crónica de Alfonso VII.

Precisamente será la Primera Crónica General de España del siglo XIII la que empieza a introducir el nombre de Marruecos para los episodios posteriores al siglo XII (GONZALBESCRAVIOTO, 2015: 9).

En el siglo XVI, existían dos grandes bloques políticos formados, a su vez, por dos reinos, al norte el de Fez y al sur el de Marrakech; estos dos estados se unirían finalmente en el siglo XVII, conformando Marruecos con la dinastía de los Alauíes (GONZALBES-CRAVIOTO, 2019).

Por tanto, el Marroquíes que conocemos y que ya era nombrado como tal en el siglo XV y con toda probabilidad en el siglo anterior, no creemos que haga referencia a los originarios de este país, entre otras cosas porque este no existía como tal, aunque sí pudiera tener relación con la ciudad de Marrakech.

\subsection{Marroquín/ De Marruecos/ Marroquí}

El adjetivo "Marroquín" se encuentra recogido en el diccionario de la RAE, como un arcaísmo, que al igual que Marroquíes, significaba natural del Marruecos. Según el estudio realizado por Bartolomé Marcos (2009) se trataría de un alias que derivaría en un apellido. Este mismo autor indica que su origen proviene de un apodo que recibió a finales del siglo XIII Sancho Ortiz, el cual fue rehén en el Magreb. Con este seudónimo, o derivados de él, se denominaba no solo a Sancho Ortiz, sino a varios grupos de cristianos mozárabes expulsados al Magreb en el siglo XII, más concretamente en 1126, y que serán devueltos a Toledo y Aragón en 1175.

Jean Pierre Molénat (1994: 2) ${ }^{3}$ indica que, en el siglo XIII, en Toledo, hay personajes que tienen la nisba al-Murrākušīy pone ejemplos como Domingo b. Yuwān al-Murrākušī (1216), o una pareja formada por Dominga al-Murrākušī y su marido Domingo Rodrigo al-Murrākušī (1251), que eran descendientes, probablemente, de los mozárabes llevados por los almorávides a Marruecos.

En el año de 1126, el rey Alfonso I de Aragón, llamado el Batallador, atacó y sitió la ciudad de Granada. Según las crónicas, principalmente al-Ihāta y al-hulal al-mawšiyya, fueron los cristianos de Granada los que animaron al rey a tomar la ciudad. No obstante, no consiguió que cayera, ya que los almorávides estaban avisados. Entonces, el monarca acusó a ibn al-Qallās, jefe mozárabe, del fracaso de la contienda. Se cruzaron recriminaciones echándose mutuamente la culpa de la derrota, por una parte, el rey argumentó que le había hecho creer que la toma de Granada sería sencilla, mientras que el segundo, Ibn al-Qallās, culpó al rey por haber avanzado con lentitud (SERRANO, 1991).

3. Hipótesis compartida por GIMÉNEZ (2006: 184). 
Las consecuencias de estas y otras actuaciones se vieron reflejadas en una fetua dictada por ibn Rušd, por la que eran expulsados los mozárabes andalusíes preferentemente de Granada, Sevilla y Córdoba. Después de esta orden numerosos mozárabes fueron deportados al Magreb, en principio a los alrededores de Mekínez y Salé, donde conservaron su culto e incluso se les autorizó a construir una iglesia en Marrakech. Muchos de estos mozárabes fueron inscriptos en el registro militar o dīwām que los almorávides utilizaron para su guardia personal y posteriormente contra los almohades (SERRANO, 1991).

Años más tarde, en 1138, y en 1170 ya con los almohades, se volvieron a producir nuevas deportaciones (SERRANO, 1991).

La población mozárabe de al-Andalus debió de quedar muy reducida, aunque, no obstante, tras la deportación de 1138, aún debían de quedar mozárabes en territorios andalusíes, siendo en 1162 cuando esta población fue casi exterminada o exiliada (SERRANO, 1991). En el caso de Jaén, a pesar de que la ciudad fue sitiada por los almohades, no consiguieron tomarla ante la defensa del visir de Ibn Hamusk, señor de Jaén. Será en 1165 cuando los almohades comienzan una acción sistemática contra este y su aliado y yerno, Muhámmad ibn Mardanís, el llamado rey Lobo. Serán precisamente las desavenencias entre ambos, además del avance y presión de los almohades, las que provocaron que en 1169 Ibn Hamusk pasara al bando de los almohades y estos lo mantuvieran como gobernador de toda la provincia de Yayyan (SALVATIERRA, 2006).

Jaén en ese momento, en el siglo XII, formaba parte del territorio almohade. Por tanto, si el nombre de Marroquíes deriva de propiedades pertenecientes a la familia de los Marroquines o de los al-Murrākušì, estos debieron de ser descendientes de aquellos que volvieron entonces de Marruecos, y que tras la conquista cristiana de Jaén recibirían tierras.

El nombre de Marroquines podría proceder de estos mozárabes que habían sido deportados a Marrakech y luego retornados, y el topónimo de Marroquíes en las tierras de la ciudad de Jaén y su entorno, como primera hipótesis puede proceder de propiedades pertenecientes a estos Marroquines, a pesar de que el apellido haciendo referencia al lugar de procedencia, según González Jiménez (1987) no era demasiado frecuente en la Castilla del siglo XIII. Sin embargo, en algunas ocasiones, como el caso de Jerez se pudo constatar que el 52,20\% de los repobladores figuran inscritos con apellidos de lugar (GONZÁLEZ, 1987 : 114), por lo tanto, sí que parece una práctica habitual.

Personajes apellidados Marroquí aparecen en la documentación referente a los repartimientos de Sevilla, Écija y Jerez, y de Valencia, en los que también encontramos el topónimo de Marroquín o Marroquí que hemos visto con anterioridad y que pertenecía a un importante linaje de Vizcaya. Juan González Marroquí, Martín Marroquí, Rodrigo Marroquí en los repartimientos de Sevilla; Sancho Ruíz Marroquí en los repartimientos de Écija, etc. (SÁNCHEZ, 2006). María de Marroquí citada en el repartimiento de Valencia (GIMÉNEZ, 2006: cita 147).

En la ciudad de Murcia existía una escuela de traductores en el siglo XIII, en la que destacaba la figura de fray Domingo Marroquí, conocido como Dominicus Marrochinus, el mismo topónimo pero en latín, que para el investigador Giménez (2006: 184) tiene origen mozárabe.

Otra segunda posibilidad es que dicho topónimopertenezcaaunlinajejudeoconverso. En el siglo XV existía en Jaén una familia de judeoconversos conocida como "López de Marruecos". Este linaje ocupaba cargos importantes en la ciudad, de hecho, uno de ellos fue alcalde de Jaén. Dicho personaje aparece en las crónicas del condestable Iranzo (Cuevas, et alii, 2001: 54). Juan López de Marruecos fue asesinado en Torredelcampo, en el motín anticonverso en 1473; otros miembros de su familia fueron procesados en el tribunal de la Santa Inquisición en 1483 y 1508 (ECHEVARRIA, 
2013). ¿Pudo ser esta familia la propietaria de estas tierras?

Existen algunos casos, aunque no era lo habitual, en los que judíos conversos son propietarios o arrendatarios de tierras. Es el caso de Pedro Núñez de Marruecos, que arrendó unas tierras del concejo de Jaén en Noalejo en 1552. Este linaje procedía del ya mencionado Juan López de Marruecos que fue asesinado en Torredelcampo en 1473. Como indica L. Coronas (1996), son escasos los propietarios de tierras entre los judíos. No obstante, debieron de conservar este tipo de propiedades hasta bien entrado el siglo XVI, cuando se producen procesos de confiscaciones de bienes raíces, por lo que a partir de este momento se produjo la acumulación de bienes fácilmente transportables (CORONAS, 1996).

\subsection{Marroquinería}

Existen otras palabras que derivan de la misma raíz, pero su significado ya no tiene nada que ver con el gentilicio; es el caso de la palabra marroquineros, o los marroquines.

En el primer caso, el término de marroquineros, según el diccionario de la RAE, se refiere a personas que se dedican a la marroquinería o industria del cuero. Por tanto, son artesanos que elaboran artículos de este material. Jaén aparece en las fuentes árabes por la importancia de los productos de la huerta, por sus árboles frutales, la miel y la industria de la seda. Sin embargo, la marroquinería no es referida como una de las industrias características de la zona. Por tanto, y en principio, no nos sugiere ninguna hipótesis sobre la relación de estos con las huertas y los trabajos agrícolas.

Por otro lado, el área denominada Marroquíes Bajos ha sido excavada y estudiada casi en extensión, y aunque su situación extramuros y la abundancia de cursos de agua la convertirían en el lugar indicado para la ubicación de esta industria o complejo artesanal ${ }^{4}$, no se han encontrado elementos estructurales que podamos atribuir a esta producción y menos aún a una gran industria. El proceso para la limpieza, preparación y curtido de las pieles se realizaba en las tenerías que eran edificios con una serie de elementos comunes, galerías abiertas o cubiertas en parte y porticadas en las que se encuentran balsas o pilones para el remojo de las pieles, y los noques (pequeños estanques o pozos donde se ponen a curtir las pieles). Es verdad que, si bien Marroquíes Bajos ha sido excavada casi en su totalidad, la parte alta, la denominada Marroquíes Altos apenas si ha podido ser estudiada desde el ámbito de la arqueología. La urbanización de la zona se realizó entre principios y mediados del siglo XX, cuando la normativa no "obligaba" a realizar ninguna actuación arqueológica. Por tanto, no podemos asegurar que en la zona no hubiera alguna estructura de este tipo.

La extensión del área que recibió el nombre de Marroquíes es demasiado amplia para circunscribirse a una sola industria, de la que, por otro lado, y como ya hemos dicho, tampoco hay referencias documentales ni evidencias arqueológicas que pudieran avalar, en época islámica, una importante industria de este tipo. Durante el periodo bajomedieval cristiano y moderno se habla de la abundancia de las tenerías. Martínez de Mazas indica que había cinco tenerías en la collación de la Magdalena, dos vinculadas a los Condes del Villar, y otras dos que compró el condestable Miguel Lucas de Iranzo y que posteriormente fueron donadas al Cabildo de la Santa Iglesia, las cuales lindaban en el año 1643 con otras tenerías propiedad de Luis Coello (MARTÍNEZ DE MAZAS, 1996: 285), como vemos todas ellas, al menos en el siglo XV, localizadas intramuros.

A partir de 1427, se firma un acuerdo entre los regidores de Jaén e Inés Solier en nombre de su hijo Pedro de Torres, por el que

\footnotetext{
4. Este tipo de industrias se implanta fuera de las ciudades por ser muy contaminantes, por lo que se elegían lugares cerca de una localidad, junto a ríos o arroyos.
} 
adquieren los estancos de todas las tenerías de Jaén, que pasan a pertenecer a la casa de los Torres (MOLINA, 1983). Como hemos visto con anterioridad, el Condestable Miguel Lucas de Iranzo compra dos situadas en la collación de la Magdalena, las primeras las adquiere en 1462 y las segundas en el año 1471 (RODRíGUEZ, 1988).

Ricardo Córdoba (1996) indica que a medida que avanza la Edad Media, los cabildos municipales intentan ubicar las tenerías fuera de las murallas; en el caso de Jaén en el arrabal de la ciudad. Será en este momento, cuando comiencen a proliferar las tenerías en el exterior de la ciudad. A finales del siglo XVIII, Martínez de Mazas, además de las mencionadas anteriormente situadas intramuros, en el barrio de la Magdalena y de las que había noticia ya en el siglo X, nombra otras localizadas extramuros: el Campillejo de San Agustín, Callejón de la Fontanilla, calle del Matadero y el solar del Arrabalejo (MARTINEZ DE MAZAS, 1996; RODRIGUEZ, 1996), pero ninguna ubicada en la zona de estudio.

En la industria de la marroquinería, como curtientes, además de otros, se empleaba una planta llamada summāq o zumaque. Dicho arbusto se cultivaba en el reino de Jaén. E. García (2020) recoge varios libros de agricultura de la época en los que se hace referencia a su cultivo tanto en secano como en regadío. Su producción parece que fue en aumento a partir de la segunda mitad del siglo XV, extendiéndose a costa de otros cultivos como viñedos y olivares. Es en este momento cuando empieza a exportarse a otros lugares de Andalucía, especialmente a Sevilla, que tenía una importante industria del curtido (OTTE, 2008: 82). En la baja Edad Media el zumaque se cultivaba, esencialmente, en Jaén y en Salamanca (AYALA et alli, 2004: 165). Esta abundancia del zumaque se dará hasta bien entrado el siglo XVII cuando su cultivo se vea sustituido por plantaciones de trigo y viñas (SANCHEZ, 1978).

\subsection{Suaeda spicata. Marroquines}

Por último, hay otra posibilidad sobre la procedencia de este topónimo. Una planta cuyo nombre científico es Suaeda spicata, pero que popularmente se conoce, entre otros nombres como Marroquines y de cuyas cenizas se extraía la sosa. Esta planta es característica de suelos compuestos de arenas y margas, siempre salinos. Aparece en el litoral y en el interior en zonas encharcadas formando pastizales que se secan en verano. Esta especie aparece en la zona más próxima al área de estudio, en el Arroyo Salado y en el lecho del Guadiana Menor (MARCHAL et alii, 2000). El suelo de la Zona Arqueológica y de su entorno más inmediato está constituido fundamentalmente por margas; probablemente, una vez abandonadas las numerosas estructuras hidráulicas de época califal provocaron un importante encharcamiento (SERRANO, 1997) que podría causar la proliferación de esta planta. No obstante, tampoco nos parece este un argumento de peso para afirmar, ni siquiera suponer, que este podía ser el nombre y el motivo del topónimo de Marroquíes.

\section{CONCLUSIONES}

Si la toponimia sirve para conocer las funciones y el significado que los pobladores dan al paisaje (ZAFRA, 2004), iqué función y que significado tenía este paraje de la ciudad de Jaén en el medievo?

En este caso no partimos, como haría la arqueología del paisaje, de un topónimo para reconocer o localizar un yacimiento, sino que, todo lo contrario, conocemos el yacimiento, pero este tiene un topónimo que, en principio, no posee ningún significado atribuible a las funciones que ha tenido a lo largo de la historia, que como hemos visto era fundamentalmente la agricultura. Entonces ipor qué los pobladores de este entorno cercano a Jaén le asignaron este nombre?

De hecho, este no es un topónimo demasiado frecuente en el territorio peninsular, al 
menos nosotros no hemos encontrado parajes, poblaciones o accidentes geográficos que lleven este nombre. Sin embargo, en el entorno de la ciudad de Jaén, sí que aparecen al menos algunos elementos más con esta denominación. Se trata de El Cortijo el Marroqui (Castillo Locubín), El monte "Marroquí", en cuya cumbre lindan los términos de Valdepeñas, Castillo de Locubín y Alcalá la Real (LÓPEZ, 2018), siendo durante el amojonamiento de esta última población, en el siglo XVI, cuando el topónimo aparece nombrado varias veces.

En estas breves líneas, tras haber realizado una exhaustiva revisión de la documentación y bibliografía existente, incluida la de los autores ${ }^{5}$ que han investigado las fuentes islámicas para el territorio que abarca este estudio, se han planteado varias posibilidades:

La industria de la marroquinería ha sido la primera posibilidad que hemos descartado, ya que ni las investigaciones arqueológicas realizadas ni las fuentes documentales nos indican tal posibilidad. Aunque hay varios factores que podrían favorecer la instalación de una industria de estas características en la zona de estudio, como es su situación extramuros y la abundancia de cursos de agua con arroyos que atraviesan toda la zona, no se han podido localizar estructuras relacionadas con dicha industria. En época cristiana las fuentes documentales hablan de la abundancia de las tenerías, pero todas ellas, al menos hasta bien entrado el siglo XV, se localizaban intramuros y sabemos que el topónimo estaba ya consolidado al menos en 1401. Otra posibilidad es que el nombre se refiera no al curtido de la piel, sino a la manufactura y venta de este tipo de artículos de piel ya curtida, en cuyo caso se trataría de establecimientos incluidos dentro de un mercado, probablemente situado en el interior de la ciudad. La única relación que hemos encontrado entre la marroquinería y la zona denominada Marroquíes es el zumaque, arbusto que se cultivaba en el reino de Jaén y por lo que era conocido ya desde época islámica, aunque su producción fue en aumento a partir de la segunda mitad del siglo XV. A pesar de ser una planta íntimamente asociada a la marroquinería, aquí solo se cultivaba, sin estar asociada realmente a la transformación y elaboración de los productos de la piel curtida.

Otra posibilidad son los marroquines que hacen referencia a una planta cuyo nombre científico es Suaeda spicata la cual, como vimos con anterioridad, se reproduce en áreas encharcadas, característica de la zona. Esta planta posee una raíz poco profunda y muy ramificada, por lo que identificar su presencia a nivel arqueológico es complicado, sin que la documentación escrita aporte ninguna noticia sobre el tema.

Por tanto, podemos descartar estas hipótesis, ya que las primeras referencias que tenemos sobre marroquíes se refieren a la casa de los marroquíes o al barranco de los marroquíes, elementos que no pueden ligarse a una planta o a una manufactura como la marroquinería, sino que parecen estar vinculados a un linaje de personas procedentes o que han estado un tiempo en Marrakech, por lo que recibieron este gentilicio. Con esta posibilidad hemos visto que, según la documentación escrita, teníamos dos posibilidades: las familias con apellido de Marroquín, mozárabes que estuvieron como rehenes o como deportados en la ciudad de Marrakech, y el linaje de judeoconversos al que pertenecía "López de Marruecos".

Esta última familia aparece en la documentación en Jaén desde 1457 (ECHEVARRIA, 2013) aunque probablemente ya residiera en la ciudad con anterioridad. Como hemos visto, es una familia judeoconversa arraigada en la comarca y con cierto prestigio, que ocupaba cargos importantes, pero siempre o casi

\footnotetext{
5. F. Javier Aguirre Sádaba y Mª. Carmen Jiménez Mata (1979): Introducción al Jaén islámico (Estudio Geográfico-Histórico), en ninguna de estas obras se ha encontrado referencia al topónimo de Marroquíes. Antonio Olmo López en su tesis Las subbéticas islámicas (Jaén-Granada). Un paso regional de evolución territorial en la cual se realiza la descripción de una serie de lugares en los que no hemos encontrado ningún topónimo que podamos relacionar con el objeto de este estudio.
} 
siempre como funcionarios, entre ellos: secretario, regidor, soldado, etc., no parece que sean grandes terratenientes rurales propietarios de numerosas fincas destinadas al cereal o similar.

El otro caso al que nos referimos son los mozárabes expulsados a Marruecos y que más tarde volvieron a la Península. Aunque las fuentes los sitúan, al menos inicialmente, en Toledo o en Aragón, sabemos que reciben tierras en los repartimientos de Sevilla, lo que los sitúa, un siglo más tarde, en el sur. En Jaén, desgraciadamente, los documentos referentes a dichos repartimientos no se conservan, por lo que, por ahora, queda solo en una simple, pero creemos que muy probable, hipótesis.

\section{BIBLIOGRAFÍA}

AGUIRRE SÁDABA, F. Javier; JIMÉNEZZ MATA, Må. Carmen (1979): Introducción al Jaén islámico (Estudio Geográfico-Histórico). Jaén: Instituto de Estudios Giennenses.

ALCÁZAR HERNÁNDEZ, Eva Må. (2008): Aldeas y Cortijos Medievales de Jaén. Jaén: Instituto de Estudios Giennenses.

AYALA MARTÍNEZ, Carlos; CANTERA MONTENEGRO, Enrique; CAUNEDO DEL POTRO, Betsabé; LALIENA CORBERA, Carlos (2004): Economía y Sociedad en la España Medieval. Madrid: Istmo.

BARTOLOMÉ MARCOS, Luis (2009): "Algunas notas acerca del origen del apellido "Marroquín”, ASCAGEN 2, pp. 71-83.

CÓRDOBA DE LA LLAVE, Ricardo (1996): "Arqueología de las instalaciones industriales en época medieval en la península ibérica. Estado de la cuestión", Medievalismo: Boletín de la Sociedad Española de Estudios Medievales, nº, pp. 193-212.

CORONAS TEJADA, Luis (1996): "Presencia de los judíos en Sierra Magina”, Sumután, nº 6, pp. 15-22.

CUEVAS MATA, Juan; DEL ARCO MOYA, Juan; DEL ARCO MOYA, José (2001): Relación de los Hechos del muy magnífico e más virtuoso, el Señor don Miguel Lucas, muy digno Condestable de Castilla. Jaén: Universidad de Jaén.

DEL ARCO MOYA, Juan (2002): "El Catastro del Marqués de la Ensenada en el archivo provincial de Jaén", Boletín del Instituto de Estudios Giennenses, n 180, pp. 19-56.

ECHEVARRÍA ARSUAGA, A. (2013): Caballeros en la Frontera. La Guardia Morisca de los Reyes de Castilla (1410-1467). Madrid: UNED

FIERRO M. (2009): "Alfonso Xel Sabio. ¿El último califa almohade?", Encuentros Medievales (2009), pp. 175-198. Recuperado de: https:// books.openedition.org/pumi/38223?lang=es
GARCÍA-PULIDO, L.J.; BRAZILLE NAULET, V. (2010): "El pago agrícola del Fatinafar (Granada) y los elementos patrimoniales conservados en el mismo", erph-revista electrónica de patrimonio histórico, 6, pp. 1-33. Recuperado de: https://revistadepatrimonio.es/index. php/erph/article/view/79/63

GARCÍA SÁNCHEZ, E. (2020): "Alimentación y paisajes agrícolas en al-Ándalus", Revista Ambienta, n⿳0126. Recuperado de: http://www. revistaambienta.es/WebAmbienta/marm/Dinamicas/secciones/ articulos/Expiracion.htm

GIMÉNEZ REÍLLO, A. (2006): "El árabe como lengua extranjera en el s. XIII", en Thomas de Antonio, Giménez Reíllo (coods.), El saber en Al-Andalus, Vol. 4, pp. 147-187.

GONZALBES-CRAVIOTO, E. (2015): "Aspectos y problemas del Marruecos Antiguo”, Hespéris-Tamuda, pp. 9-42.

GONZALBES-CRAVIOTO, E. (2019): "El Nombre Antiguo de Marruecos. De La Mauretania Tingitana a Marruecos", Hespéris-Tamuda LIV (1), pp. 11-40

GONZÁLEZ JIMÉNEZ, M. (1987): "Repartimientos andaluces del siglo XIII, perspectivas de conjunto y problemas", Historia, Instituciones, Documentos, $n^{0} 14$, pp. 103-122.

LILLO, J. L.; ÁLVAREZ, J. M. C. (2006): "Contabilidad y cobros de rentas en la Santa Capilla de San Andrés. Dos siglos y medio tras la búsqueda de la eficiencia (1650-1900)", DE COMPUTIS, Revista Española de Historia de la Contabilidad, n 4, pp. 68-118. https:// doi.org/10.26784/issn.1886-1881.v3i4.204

LLORENT-VEDMAR, V. (2014): "Identidad cultural bereber y enseñanza del amazigh", Revista Española de Educación Comparada, 23, pp. 53-75. https://doi.org/10.5944/reec.23.2014.12297

LÓPEZ ARANDA, M. A. (2004a): "Formación y relaciones de poder de un patrimonio eclesiástico. La Santa Capilla de San Andrés de Jaén", en F. J. Aranda Pérez (ed), El mundo rural en la España Moderna, pp. 1171-1184.

LÓPEZ ARANDA, M.A. (2004b): "Sombras de Sierra Magina en la fundación del Colegio del Santísimo Sacramento", Sumuntan, $n^{\circ}$ 21, pp. 21-83. Recuperado de: https://www.cismamagina.es/app_ sumuntan/pdf/21/21-83.pdf

LÓPEZ CORDERO, J.A. (2003): Jaén tras la muralla (Primera expansión, 1500-1950), pp. 83-87. Granada.

LÓPEZ CORDERO, J. A. (2018): "El camino viejo de Jaén a Baeza", en E. Escobedo Molinos, J. A. López Cordero y M. Cabrera Espinosa (eds.), VI Congreso virtual sobre Historia de las Vías de Comunicación, pp. 225-249. Recuperado de: https://www.revistacodice.es/ publi_virtuales/vi_c_h_camineria/comunicaciones/lopez-cordero-camino-jaen-baeza.pdf

MARCHAL, F.; TORRES J.A,; SALAZAR, C.; SILES, G.; CANO, E. (2000): "Notas sobre la vegetación semiárida en las estribaciones de sierra Pagina", Sumuntán, n 13, pp. 83-90.

MARTÍNEZ DE MAZAS, J. (1996): Retrato al Natural de la Ciudad y Termino de Jaén. Barcelona. Recuperado de: http://www.bibliotecavirtualdeandalucia.es/catalogo/catalogo_imagenes/grupo. cmd?path=20034;

MARTÍNEZ GÁZQUEZ, J. (2011): "Marruecos/Marrakech tierra de acogida en los textos latinos de controversia islamo-judeo- 
cristiano", Myrtia. Revista de filología clásica, n² 26, pp. 141-148. Recuperado de: https://revistas.um.es/myrtia/article/view/143711

MARTíNEZ IGNACIO, A. (2009): "Vocabulario Medieval contenido en el Texto y documentos", Antigüedad y cristianismo: Monografías históricas sobre la antigüedad tardía, n 26, pp. 327-340. Recuperado de: https://revistas.um.es/ayc/article/view/388131

MOIÉNAT, J.P. (1994): "L'arabe à Tolède, du XII au XVI siclé", Al-Qantara, n² 25, pp. 473-488.

MOLINA MARTÍNEZ, M. (1983): "Los Torres y Portugal. Del señorío de Jaén al virreinato peruano", II Jornadas de Andalucía y América, pp. 35-76

NAVARRO PÉREZ, M. (2017): La ocupación del entorno de las ciudades en época omeya. Marroquíes Bajos. Jaén. (Tesis doctoral). Jaén: Universidad de Jaén. Recuperado de: p.[http://hdl.handle. net/10953/]

NAVARRO PÉREZ, M. (2018): "La maqbara del camino de Bayyāsa (Marroquíes Bajos. Jaén)", Lucentum, XXXVII, pp. 281-303. https:// doi.org/10.14198/LVCENTVM2018.37.16

OTTE SANDER, E. (2008): Sevilla, siglo XVI: materiales para su historia económica. Sevilla.

PÉREZ ALVARADO, S. (2003): "Un indicador arqueológico del proceso de islamización. Las Cerámicas Omeyas de Marroquíes Bajos”. Jaén.

PORRAS ARBOLEDAS, P.A. (1997): «La ciudad de Jaén (1246-1525). Avatares políticos e institucionales de una ciudad fronteriza», España Medieval n 20; pp. 195-218.

PORRAS ARBOLEDAS, P. A. (2009): "El régimen de alcaldías y veedurías en el concejo bajomedieval: el alcalde del alarifazgo en Jaén", Estudios de Historia de España, 11, pp. 123-163. Recuperado de: http://erevistas.uca.edu.ar/index.php/EHE/article/ view/130/133
QUESADA QUESADA, T. (1994): El paisaje rural de la campiña de Jaén en la Baja Edad Media según los libros de dehesas. Jaén.

RODRÍGUEZ MOLINA, J. (1988): "Inventario de documentos de la Catedral de Jaén, realizado en 150", Cuadernos de estudios medievales y ciencias y técnicas historiográficas, nº 14-15, pp. 159175. Recuperado de: http://digibug.ugr.es/bitstream/10481/30278/1/ CEM-014-015.001-Art\%C3\%ADculo-009.pdf

RODRÍGUEZ MOLINA, J. (1996): La vida de la ciudad de Jaén en tiempos del Condestable Iranzo. Jaén: Concejalía de Cultura. Servicio de Publicaciones

SALVATIERRA CUENCA, V. (2006): El Alto Guadalquivir en época islámica. Jaén: Universidad de Jaén.

SÁNCHEZ SALAZAR, F. (1978): "La real sociedad económica de amigos del país de Jaén (1786-1820)", Hispania, Vol. 38, n Extra 9, pp. $113-114$

SÁNCHEZ SAUS, R. (2006): "Los caballeros jerezanos en la "Nómina de la Frontera” de 1290”, La España Medieval, n² 29, pp. 31-35.

SERRANO PEÑA, J.L. (1997): "Un Complejo Califal de Marroquíes Bajos", Arqueología y Territorio Medieval, n 4, pp. 59-80. Jaén. https://doi.org/10.17561/aytm.v4i0.1642

SERRANO RUANO, D. (1991): "Dos fetuas sobre la expulsión de mozárabes al Magreb en 1126", Anaquel de Estudios árabes, n² 2, pp. 163-182.

ZAFRA DE LA TORRE, N. (2004): "Nombrar, apropiar. Arqueología del paisaje y toponimia en la aldea de Otíñar (Jaén), (1300-2000 DNE)", Arqueología y Territorio Medieval II.I, pp. 23-58. Jaén. https:// doi.org/10.17561/aytm.v11i1.1701 